\title{
PAIN IN THE ARM : A REVIEW
}

BY

\section{H. LOVELL HOFFMAN}

Hon. Assistant Physician to the Royal United Hospital and the Royal National Hospital for Rheumatic Diseases, Bath

No one will deny the common occurrence of pain in the arm, nor the frequency with which the diagnosis of brachial neuritis was formerly made in such cases. Nevertheless, the pathology of brachial neuritis has not yet been described convincingly, and in recent years attention has been focused upon certain other common syndromes, the study of their well-defined morbid anatomy leaving little doubt that they are responsible for a very large proportion of cases of pain in the arm. We now believe that brachial interstitial neuritis is a comparatively uncommon condition and that this diagnosis should be made only rarely, when all other causes of brachial pain have been excluded.

The accompanying Table gives a fairly comprehensive list of the causes of the symptom in question, arranged roughly according to the site of the lesion, but only five syndromes will be discussed in detail, namely: the root symptoms and signs of spondylitis; prolapse of a cervical intervertebral disc; compression at the thoracic outlet; brachial neuritis; referred pain.

\section{Examination and Interpretation of Physical Signs}

Before proceeding, it may be well to reconsider certain elementary principles. A complete history and physical examination are essential, and should include the whole nervous system, the joints and the muscles, in which signs of weakness, wasting, or localized tender areas should be noted. In those cases where there is evidence of nerve involvement, it must be determined whether the lesion is in the cord, the nerve roots, the brachial plexus, or the peripheral nerves, and an accurate knowledge of the skin areas and muscles supplied by the roots and peripheral nerves is essential for this purpose. But when considering sensory loss due to root lesions it should be remembered that there is considerable overlap of the dermatomes supplied by each spinal root, and thus sensory loss can only be expected in the area supplied solely by the affected root. Proximally this area may be too narrow to map out, but pain from a root lesion will be felt throughout the entire area supplied by that root, even in the narrow proximal area just mentioned, and may overlap other dermatomes. Paraesthesiae from root lesions are similarly distributed, but tend to be felt more in the distal part of the limb.

In a complete lesion of a peripheral nerve the area of sensory loss to light touch is greater than that to pin-prick, whereas in a complete root lesion the opposite is found. Progressive compression of a nerve without total interruption of conductivity also produces a greater area of loss to pin-prick than to light touch; this is responsible for the dissociated anaesthesia which may be found in cases of cervical rib.

It is comparatively easy to differentiate the muscle weakness or wasting in a complete root or peripheral nerve lesion. But in progressive compression certain muscles will be more affected than others and confusion will arise. Further, the nerve supply of most muscles receives components from several roots, a single root lesion rarely causing complete muscle paralysis.

In conditions producing referred pain, there will be, of course, no signs of organic neurological disturbance, but wasting of the small hand muscles occurs in many cases of rheumatoid arthritis and may easily be mistaken for the effects of a nerve lesion.

\section{Nerve Symptoms and Signs in Spondylitis}

The neurological symptoms of vertebral rheumatism have been admirably reviewed by Buckley (1945). The two most important conditions giving rise to root involvement are ankylosing spondylitis and osteo-arthritis.

In the former the symptoms occur in the early stages, when there is epidural and peri-radicular exudate. Later, fibrosis determines the permanency of the residual signs; they are not due to bony narrowing of the intervertebral foramina and are much less common when the spine has become fixed. 


\section{TABLE}

\begin{tabular}{|c|c|}
\hline $\begin{array}{l}\text { CENTRAL OR } \\
\text { CEREBRAL }\end{array}$ & thalamic pain \\
\hline $\begin{array}{l}\text { AT CORD } \\
\text { LEVEL }\end{array}$ & $\begin{array}{l}\text { spinal tumour } \\
\text { syringomyelia } \\
\text { haematomyelia } \\
\text { localized arachnoiditis } \\
\text { tabes dorsalis } \\
\text { meningo-vascular syphilis } \\
\text { poliomyelitis } \\
\text { subacute combined degeneration }\end{array}$ \\
\hline $\begin{array}{l}\text { AT INTER- } \\
\text { VERTEBRAL } \\
\text { FORAMEN }\end{array}$ & $\begin{array}{l}\text { disease of nerve root or root ganglion: } \\
\text { radiculitis } \\
\text { herpes zoster } \\
\text { neurofibroma } \\
\text { disease of vertebrae: } \\
\text { fracture } \\
\text { caries } \\
\text { osteomyelitis } \\
\text { Paget's disease } \\
\text { new growth } \\
\text { displaced discs } \\
\text { spondylitis, ankylosing } \\
\text {," osteo-arthritic } \\
, " \quad \text { rheumatoid }\end{array}$ \\
\hline
\end{tabular}

AT cervical rib

THORACIC abnormal first rib

OUTLET costo-clavicular compression

normal first rib pressure

scalenus syndrome

acroparaesthesiae

glands and tumours

IN THE ARM

pressure and trauma:

fracture

occupational neuritis

trauma in ulnar groove

pressure on median nerve

in carpal tunnel

pressure in palm

causalgia

neuritis:

polyneuritis

toxic neuritis (e.g., arsenic, alcohol)

interstitial neuritis

paralytic brachial neuritis

referred pain:

from visceral disease (e.g., angina pectoris

from skeletal disease (bones, joints, tendons, muscles, "myalgic lesions", "fibrositis")

vascular disease:

thrombosis

embolism

Raynaud's phenomenon

Sciatic pain is well known as an early symptom of the disease, and is often considered to be referred from an affected sacro-iliac joint; but if there are signs of a root lesion, such as sensory loss or an absent ankle jerk, pressure on a nerve root in the lumbosacral region must be held responsible.
In osteo-arthritis root symptoms and signs are more common. Some cases of so-called "brachial interstitial neuritis" are due to this cause. It may also produce occipital headache when the first, second, and third cervical roots are involved; such cases are often wrongly diagnosed as primary "fibrositis". We shall see later how tender nodules may be associated with nerve-root irritation in this and other syndromes, so adding to the difficulty of diagnosis. Signs of nerve-root irritation frequently arise before demonstrable osteophytes are present, being produced while the osteophytes are forming. Soft-tissue changes, and not pressure from new bone, are thus probably responsible. On the other hand, symptoms may not occur until osteo-arthritis has been present for years. In this case it frequently happens that the roots irritated arise from that part of the vertebral column which shows least evidence of osteophyte formation and which is still comparatively mobile; a certain degree of mobility is usually necessary to cause root irritation. Various factors may produce an exacerbation of symptoms by causing soft-tissue reaction and swelling. These are strain or minor trauma, chill or damp, an intercurrent infection, or a septic focus.

Symptoms and Signs.-All the symptoms and signs of root pressure may be encountered, namely pain and paraesthesiae of root distribution, muscle weakness and wasting, and alteration in reflexes. Fibrillation sometimes occurs. The neck movements are usually painful and limited in varying degrees, but, as already pointed out, the neck may actually move best around those joints which are in relation to the affected roots.

Differential Diagnosis.-Although the sixth cervical root, being the largest, is that most frequently affected, osteo-arthritis tends to involve several roots. A uniradicular lesion should always raise the suspicion of a prolapsed disc. The pain from root pressure in osteoarthritis is not so severe as that in cord or vertebral neoplasm. It is relieved by rest, and aggravated by movement. As the local soft-tissue reaction subsides, so does the pain; this also tends to occur the more nearly the neck becomes fixed. In neoplasm, both symptoms and signs progress relentlessly, and there may be signs of pressure on the cord which, of course, do not occur in osteo-arthritis.

The three-quarter profile radiograph of the cervical spine should always be taken and may reveal obstruction of the intervertebral foramina. But osteo-arthritic lipping may occur without nerve-root involvement, and its presence is no proof that the symptoms are due to this cause: the appearance is common in the sixth and seventh cervical vertebrae in prolapse of the sixth intervertebral disc.

Treatment.-In ankylosing spondylitis treatment is on the usual lines for this disease. In osteo-arthritis, superficial heat is useful, but deep heat, such as shortwave diathermy, may cause swelling of the soft tissues 

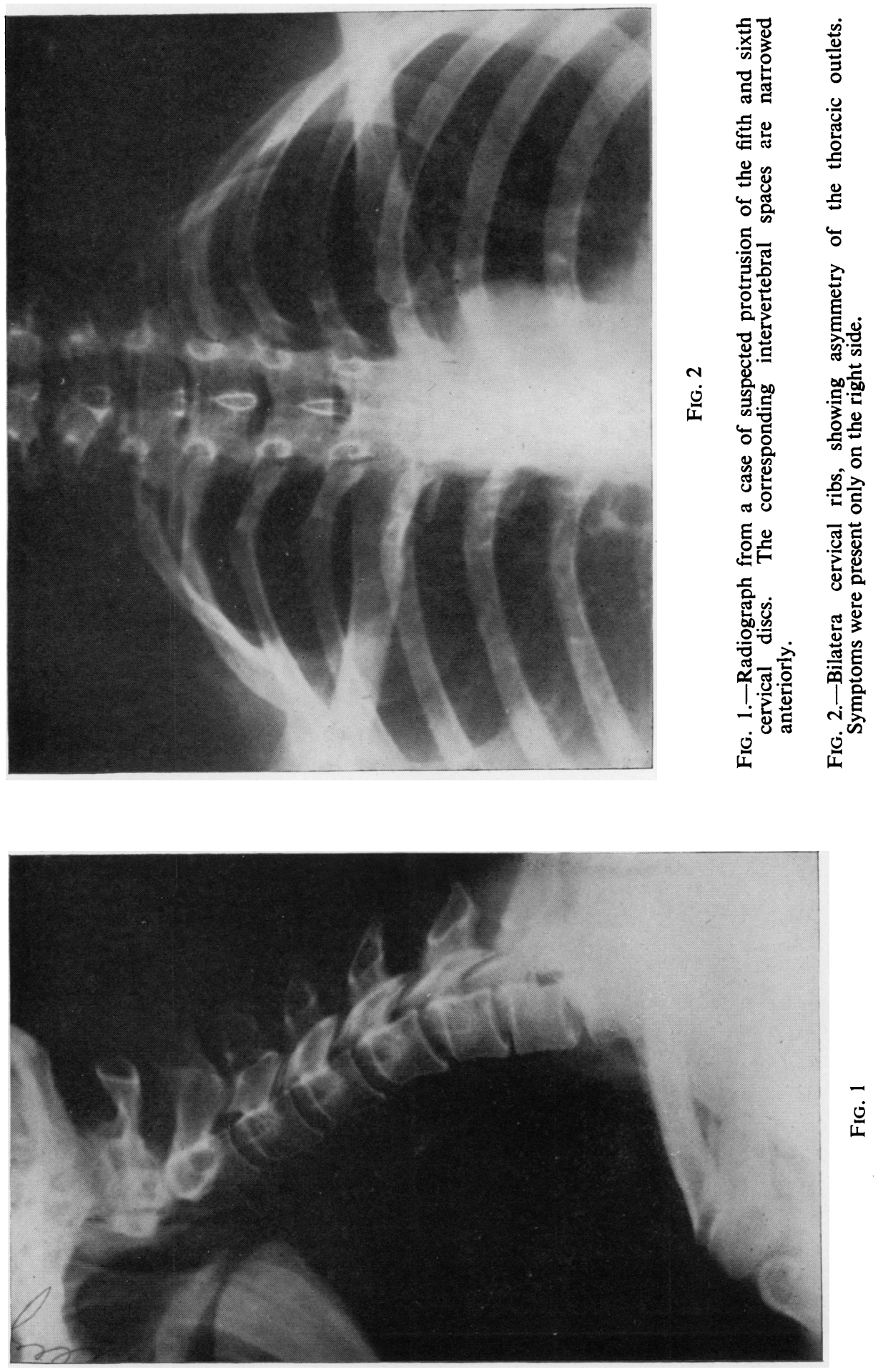

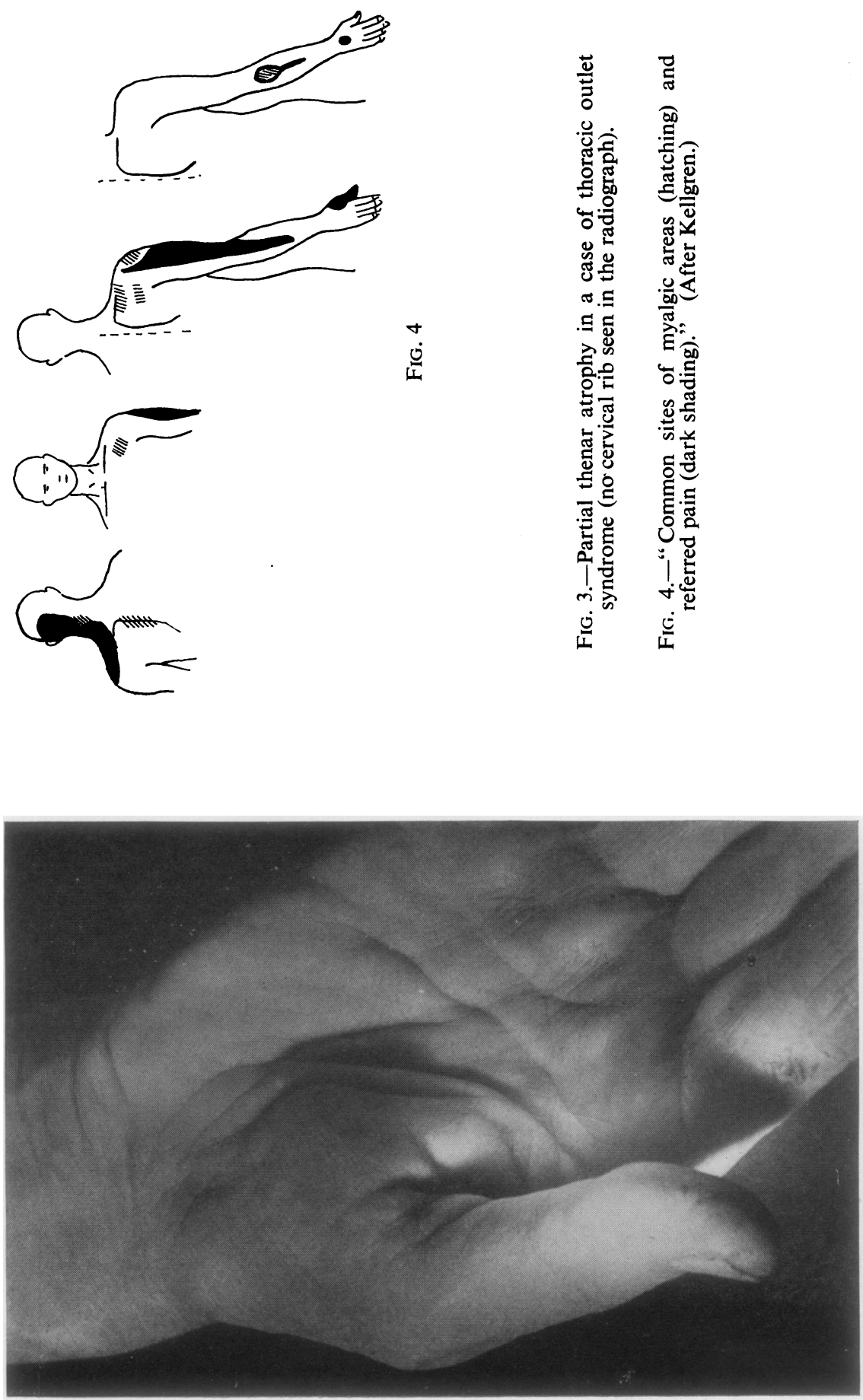

m 
and so increase the symptoms. The same applies to deep $x$-ray therapy. Neck exercises and movements should be given, and gentle massage to the neck muscles is useful. Manipulation by an orthopaedic surgeon can be carried out in some cases. The paretic muscles should receive the same treatment as in other root or peripheral nerve lesions.

\section{Herniation of a Cervical Intervertebral Disc}

Rupture of a cervical intervertebral disc may cause spinal-cord compression with associated root signs at the level of protrusion. But root compression without cord involvement can occur, giving rise solely to root symptoms and signs in the arm (Semmes and Murphy, 1943; Spurling and Scoville, 1944; Elliott and Kremer, 1945). This is usually the case when the protrusion is laterally placed, more medial lesions producing the complete syndrome. The first cervical nerve leaves the cord between the occiput and the atlas, where there is no disc, so that a lesion of the sixth disc (that between the sixth and seventh cervical vertebrae) will press on the seventh root. As the roots leave the cord at a fairly wide angle, each root passes over one disc only, in contradistinction to the condition existing in the lumbar region. Unless there are several disc protrusions, the symptoms are therefore uniradicular. Most often the seventh cervical root is affected, the sixth and fifth roots less frequently.

Pain is the chief complaint and is of a dull, gnawing character (Elliott and Kremer), often spreading from the supraspinous region to the posterior axillary fold and lateral shoulder region; thence down the outer side of the arm to the second and third digits in a lesion of the seventh cervical and to the thumb if the sixth cervical is involved. In four left-sided cases described by Semmes and Murphy, the pain was referred to the praecordium, as well as to the left arm, and, not unnaturally, in some of these coronary occlusion was at first suspected. Paraesthesiae are often present and may be severe; they are chiefly felt peripherally. Coughing, sneezing, and flexion of the head towards the side of the lesion sometimes aggravates the pain, which is often worse at night owing to flexion of the neck.

Physical Signs (in Lesions of the Seventh Cervical).Pressure on the forehead from behind, with the neck bent towards the side of lesion, may reproduce pain, but perhaps not till after the pressure has been applied for several minutes (Spurling's sign). Weakness and wasting of the triceps and extensors of the forearm may occur, but is usually slight. The triceps commonly feels flabby (Elliott and Kremer, 1945), and the triceps jerk may be diminished or absent. Sensory loss is found chiefly in the index finger, but may involve the middle finger to a less degree. (It is important to remember that in most textbooks the index finger is not considered to lie in the seventh cervical dermatome.) There is often limitation of neck movements with spasm of the neck and shoulder muscles. Tenderness may be found over the exit of the affected root and also at various trigger points, in, for example, the upper fibres of trapezius, and pectoralis major; also in the triceps and the extensor muscles of the forearm. Electromyography of these points shows a constant increased irritability. and procaine injection often relieves pain. The significance of these findings will be discussed later.

Special Examinations.-As in lumbar disc lesions, the cerebrospinal fluid may show slightly increased protein, but the dynamics of the fluid are usually normal. Incidentally, lumbar puncture sometimes causes a severe exacerbation of pain. Radiographs may show narrowing of the affected disc space (Fig. 1), with lipping anteriorly and in the region of the intervertebral foramen. This latter change can only be seen in oblique views. Opinions differ regarding the assistance given by contrast media, but it may be said that pantopaque is the only one which is of any use. With this substance Elliott and Kremer showed filling defects opposite the affected discs and lack of filling of the corresponding root sheath.

Treatment.-Owing to the presence of the spinal cord the operation for removal of a disc in the cervical spine presents far more difficulty than in the lumbar region. Fortunately conservative treatment is very often successful and should always be tried first in cases where there is only root compression. The patient should be allowed to find the most comfortable position for his neck, and his pillows should be adjusted to retain it in this position. In more severe cases head traction by harness is needed. If these measures fail, laminectomy, with removal of the offending disc, must be performed.

\section{Compression at the Thoracic Outlet (Excluding glands and tumours)}

According to Walshe and others (1944) the conditions causing compression at the thoracic outlet may be divided into two categories, namely: those in which there is some structural abnormality of the outlet, and those in which it is normal. The following are included:

\section{Cervical ribs \\ 2. Abnormal first ribs $\begin{aligned} & \text { asymmetrical outlets } \\ & \text { abs }\end{aligned}$}

3. Normal first rib pressure

4. Costo-clavicular compression

5. Scalenus syndrome

(Fig. 2)

Associated with the asymmetrical outlets there may be other developmental abnormalities, such as scoliosis, wedge-shaped vertebrae, extra half laminae, or the Klippel-Feil syndrome of fusion of several cervical vertebrae.

Symptoms and Signs.-These may be of three kinds occurring separately or together, namely: vascular, sympathetic, or somatic nervous. 
(a) VASCULAR

(1) Arterial: due to disturbance of circulation of the brachial or axillary arteries. They consist of: recurrent coldness, cyanosis, pallor, and tingling in the affected arm; symptoms due to a patent aneurysmal dilatation of the artery (pulsation and bruit above the clavicle) ischaemic phenomena, and occasionally embolism from completely or partly occluded aneurysm.

(2) Venous: due to compression of the subclavian vein.

The arterial symptoms were once thought to be due to kinking of the artery over the abnormal rib; then to interference with the sympathetic supply to the vessel. This view has been criticized by Walshe and his colleagues, who consider that the vessel can be nipped between the clavicle and the uppermost rib. In a recent article, Telford and Mottershead (1947) show that this does not occur when the shoulder is depressed, but that it does happen in a small number of cases of abnormal ribs when the shoulder is braced back or the arm is fully elevated. They point out that in depression of the shoulder the clavicle is carried forward and the costoclavicular gap is actually widened. They further state that the phenomenon of alteration of the pulse is due to compression of the artery distal to the clavicle by the two heads of the median nerve, and therefore has nothing to do with costo-clavicular compression. Clearly there is no one cause to which vascular symptoms can invariably be ascribed in these various syndromes. The variations from the normal are large, and so are the mechanisms which may be brought into play.

\section{(b) SYMPaTHETIC}

These signs, which can include Horner's syndrome on the affected side, are considered by Walshe to be due to interference with the stellate ganglion, through traction on the subclavian artery or the formation of scar tissue in the vicinity.

\section{(c) Somatic Nervous}

(1) Thenar type.-There are pain, paraesthesiae, and sometimes objective sensory loss on the ball of the thumb and the radial side of the forearm. Kinnier Wilson (1940) has described the typical partial thenar atrophy which occurs, involving the upper and outer half of the area, due to wasting of those muscles supplied by the median nerve, that is, abductor pollicis brevis, opponens pollicis, and half of flexor pollicis brevis (Fig. 3).

(2) Ulnar type.-Here pain and sensory loss occurs on the ulnar aspect of the hand and forearm, with wasting of the interossei and adductor pollicis; there may be an appearance of the main en griffe. Occasionally there is weakness of serratus anticus and winging of the scapula.

In all these syndromes it must be stressed that symptoms are due to a variety of causes operating together or separately. They have been conveniently grouped by Walshe and his co-authors as:

1. Anatomical (the variations of the thoracic outlet).

2. Pathological (soft-tissue changes, such as scar formation, following constant respiratory movement).
3. Physiological (dropping of the shoulder girdle from atonic muscles, the carrying of heavy weights, or trauma).

In cases ascribed to normal first rib pressure or the "scalenus anticus syndrome", rib, clavicle, post fixation of the plexus, and sagging of the shoulder girdle, all play their part in causing symptoms, and sometimes pressure of scalenus anticus or medius is also concerned. This is probably due to the position of the neurovascular bundle in relation to the insertion of the scalene muscles and not to the fact that they are in spasm. Such a condition is unlikely to occur if the rest of the neighbouring muscles are atonic. As Le Vay (1947) has pointed out, there is good evidence that in certain cases the clavicle may compress the neurovascular bundle against the knifelike edge of the scalenus medius.

Treatment.-Unless there are fairly marked signs of nerve damage, conservative treatment may be tried first. Massage to the muscles with "shoulder-shrugging" exercises should be carried out in an attempt to raise the shoulder girdle. If there is progressive weakness and wasting of the hand muscles, operation must be considered. This should always be of an exploratory nature, and the surgeon must be prepared to deal with the particular mechanism of compression which he discovers.

Walshe (1945) has recently drawn attention to the common syndrome of acroparaesthesiae in middle-aged and elderly women. Here sagging of the shoulder girdle due to fatigue and atonic musculature causes paraesthesiae, pain, and circulatory disturbance in both upper limbs, without gross physical signs. The condition has become common in the war and post-war years when elderly women, unaccustomed to these activities, have been forced to stand in queues and to carry shopping baskets for long periods. The treatment is rest and support of the arms in slings, with massage and exercises to restore tone to the muscles of the shoulder girdle.

\section{Brachial Neuritis}

Pain in the arm, together with muscle weakness, wasting, and sensory loss, may occur as a symptom of all the varieties of polyneuritis, in the neuritis of diabetes, and in that due to alcohol or arsenic. It is not intended to discuss these further. The diagnosis of interstitial brachial neuritis was once one of the commonest in medicine, but with our present knowledge of the morbid anatomy of the cervical region and shoulder girdle, and recent researches into referred pain and the nature of fibrositis, it is safe to say that pain in the arm should now only be ascribed to interstitial neuritis when all other possible causes have been excluded. Opportunities for examination of nerves in so-called interstitial neuritis have been very few. DennyBrown (1933) examined the sciatic nerve in one of his patients who died following oxygen injection for sciatica and found exudate under the perineurium of the individual nerve fibres. More recently Holmes and Sworn (1946) have found evidence of 
what they call " radiculitis" in certain cases of negative exploration for herniated lumbar discs. There was swelling of the affected nerve root, or adhesions around it, but of course histological examination was not possible.

There is, however, a very definite entity that has come into prominence during the war years, which is variously known as "localized neuritis of the shoulder girdle" (Spillane, 1943), " acute brachial radiculitis" (Aldren Turner, 1944), or " paralytic brachial neuritis" (Martin and Elkington, 1946). The essential features are: pain in the shoulder girdle and down the outer side of the arm, followed at varying intervals of hours, days, or weeks, by muscle weakness and wasting, usually of the shoulder girdle and upper arm. The signs may suggest involvement of (1) a single peripheral nerve (2) several peripheral nerves, or (3) nerve roots. In some cases the signs are bilateral. The serratus anticus is frequently involved, producing a winged scapula, the well-known cases of long thoracic palsy being probably examples of this syndrome. Sensory loss is found in the appropriate areas when nerves such as the circumflex or musculo-cutaneous are involved, and tendon reflexes may be lost. Constitutional and febrile disturbances are usually absent. A peculiar feature is that patients in hospital for unrelated conditions are frequently affected. The cerebrospinal fluid is normal as a rule, but occasionally there is a slight excess of protein. This helps to distinguish the condition from poliomyelitis, with which it is liable to be confused. The prognosis is variable, many cases remaining paralysed for long periods or even permanently. The treatment is that of other forms of flaccid paralysis.

There are various forms of compression neuritis and occupation neuritis. For example the ulnar nerve may suffer repeated trauma in the ulnar groove at the elbow or be affected by chronic periostitis in this region. Recently Russell Brain and others (1947) have described the syndrome of spontaneous compression of both median nerves in the carpal tunnel. It should not be forgotten that various forms of organic nerve involvement may be heralded by an occupation neurosis such as writer's cramp.

\section{Referred Pain and Fibrositis}

Disease of the shoulder joint, its ligaments, bursae, and the muscles and tendons in the vicinity, can cause pain referred to the arm. Space does not permit me to consider the conditions fully, but I would mention periarthritis of the shoulder, subacromial bursitis, and tendinitis, which are often considered together as Duplay's syndrome.

Much interesting work has recently been done on referred muscle pain, and new light has been thrown on the aetiology of fibrositis, but this can only be mentioned briefly. Kellgren in 1938 showed that muscle pain may be referred in a distribution which follows a segmental pattern and that tenderness is associated with the referred pain. In the light of this observation, he examined certain cases of fibrositis or myalgia and was able, by study of the areas of referred pain, to localize the points from which this pain arose. Novocaine injection of the primary myalgic area abolished both local and referred pain. By studying his diagrams it will be seen how such cases must often have been mistaken for interstitial neuritis, tenderness of muscle having been confused with that of nerve (Fig. 4).

Elliott (1944) has drawn attention to myalgic areas in the gluteal region in cases of sciatica due to the proved disc lesions and in the extensor muscles of the arm where cervical nerve roots are involved. He examined these with the electromyograph, and found spontaneous motor activity therein. He considers that this is due to involuntary spasm of small groups of muscle fibres caused by irritation of the motor root more centrally. He further suggests that localized spasm can be induced through a reflex path which involves the anterior horn cells, and that the source of excitation may be in or outside the actual nerve root.

Kelly (1945) believes that these myalgic lesions may sometimes arise from visceral disease, for example in the kidney or heart. . The visceral disease can cause: (a) reflex (referred) muscle spasm and deep tenderness; (b) radiation of pain impulses to the site of election in muscle, which then takes on a degree of self-sufficiency and produces (c) a myalgic lesion with the usual secondary effects. By analogy, he postulates a reflex theory for the production of post-traumatic myalgic lesions and of fibrositis in general. This is a fascinating hypothesis, and if proved will explain much that was unsatisfactory in the aetiology of fibrositis. It is fairly easy to conceive a myalgic area of muscle spasm arising as a result of any of the following conditions, which we know may be associated with fibrositis: (1) trauma; (2) local cold or damp; (3) root lesions from spinal osteo-arthritis or discs; (4) generalized muscle pains of influenza or subacute rheumatism; (5) fibro-fatty herniations (Copeman's nodes).

The primary myalgic area is usually the most tender, though the patient will often complain most of the pain in the area of reference. It is important to remember that novocaine injections should be made into the primary area. For example, a myalgic lesion in the supraspinatus causes pain to radiate into the deltoid in which a tender area may be felt. Injection in the supraspinatus will frequently relieve the pain, whereas if the deltoid is injected the pain 
will be aggravated. The same applies to pain in the forearm and hand arising from a primary lesion in the extensor muscles near their proximal attachment.

Myalgic lesions around the shoulder girdle are frequently associated with gross limitation of movement of the shoulder joint (frozen shoulder) due to periarthritis. This may require manipulation under an anaesthetic. It is interesting to speculate which arose first, the myalgic lesion, or the periarthritis.

\section{Concluding Remarks}

In concluding this review I would emphasize the following most important point: The discovery of some abnormality which is, by itself, capable of producing pain in the arm, is no proof that it is the lesion causing symptoms in this particular case. For example, myalgic or "fibrositic" spots can give referred pain, but may themselves be secondary to root lesions from other causes. Osteo-arthritic lipping is often present in cases with a disc lesion. Cervical ribs and abnormal thoracic outlets are frequently associated with other pathological conditions, notably syringomyelia. One. of the cases described by Russell Brain and others (1947) deserves particular mention here. Compression of both median nerves in the carpal tunnels was diagnosed and successfully treated by operation, despite the fact that radiographs revealed bilateral cervical ribs, a Klippel-Feil deformity of the cervical spine, and a Sprengel shoulder. The original paper should be consulted for full details, as there can be few better examples of the value of painstaking examination, and the correct interpretation of physical signs, without which the clinician will have little success in the diagnosis and treatment of the causes of pain in the arm.

\section{REFERENCES}

Brain, W. R., Dickson-Wright, A., and Wilkinson, M. (1947). Lancet, 1, 277.
Buckley, C. W. (1945). Annals of the Rheumatic Diseases, 4, 54.

Denny-Brown, D. (1933). Proc. roy. Soc. Med., 26, 1399.

Elliott, F. A. (1944). Lancet, 1, 47.

and Kremer, M. (1945). Ibid., 1, 4.

Holmes, J. MacD., and Sworn, B. R. (1946). Brit. med. J., $1,946$.

Kellgren, J. H. (1938a). Ibid., 1, 325.

(1938b). Clin. Sci., 3, 175.

Kelly, M. (1945).- Annals of the Rheumatic Diseases, 5, 1. (1946a). Ibid., 5, 69.

- (1946b). Ibid., 5, 161.

Le Vay, D. (1947). Proc. roy Soc. Med., 40, 494.

Martin, J. P., and Elkington, J., St C. (1946) Price's "Textbook of Medicine". 7th edit. Oxford University Press. p. 1795.

Semmes, R. E., and Murphy, F. (1943). J. Amer. med. Ass., 121, 1209.

Spillane, J. D. (1943). Lancet, 2, 532.

Spurling, R. G., and Scoville, W. B. (1944). Surg. Gynec. Obstet., 78, 350.

Telford, E. D., and Mottershead, S. (1947). Brit. med.J., 1, 325 .

Turner, J. W. Aldren (1944). Ibid., 2, 592.

Walshe, F. M. R., Jackson, H., and Wyburn-Mason, R. (1944). Brain, 67, 141.

Walshe, F. M. R. (1945)' Brit. med. J., 2, 596.

Wilson, S. A. K. (1940). " Neurology." Edward Arnold. London.

\section{Douleur du Bras}

RÉSUMÉ

Un tableau donne une liste complète des causes de la douleur du bras classées grosso modo en fonction du siège de la lésion. Cinq syndromes sont discutés en détail: les symptomes et les manifestations radiculaires de la spondylite; la hernie d'un disque intervertébral; la compression juxta-thoracique; la névrite brachiale; la douleur irradiante. L'examen et l'interprétation des signes physiques sont discutés. On insiste sur le fait que même dans le cas de la découverte d'une anomalie capable en elle-même de provoquer une douleur dans le bras, il n'est pas prouvé que ce soit cette anomalie qui cause les symptomes dans le cas étudié. 